\title{
Sea-level rise in ports: a wider focus on impacts
}

\author{
Aris Christodoulou $^{1} \cdot$ Panayotis Christidis $^{1} \cdot$ Hande Demirel $^{2}$
}

Published online: 17 October 2018

(C) The Author(s) 2018

\begin{abstract}
In this paper, we assess the impacts of climate change on seaports for different global warming level scenarios. The results refer to the potential risks associated with two scenarios, represented by sea-level rise projections that have been estimated considering mean sea level, tides, waves and storm surges. The comparison of the results of the two scenarios shows that $25 \%$ more cargo can be affected by extreme water levels until the end of the century, according to the high warming scenario (RCP8.5), than that according to the RCP4.5 scenario. Major European ports at risk are identified using their projected exposure to sea-level rise and extreme weather events. The size of impacts is measured in relation to the volumes of cargo handled annually. According to the high warming scenario, extreme sea level increases higher than $0.5 \mathrm{~m}$ will affect the largest part of the European coastline, while more than $1 \mathrm{~m}$ increases will occur in the North Sea, the Western part of the Baltic Sea and in parts of the British and French Atlantic coasts. Furthermore, from 2010 to 2100 , the amount of cargo to be handled in ports exposed to extreme sea levels higher than $4.5 \mathrm{~m}$ will increase by more than 200 million tonnes, while the majority of these ports will be located in Spain, UK, Ireland, Portugal and Norway. In the Black Sea and the Mediterranean, the impacts are expected to be significantly milder (lower Extreme Sea Levels) but to occur more frequently in comparison to the North Sea. The wider impacts of potential disruptions in port operations are evaluated by considering the effects on the European hinterland at regional level, and on European foreland by taking into account Europe's connections to major ports worldwide. Areas outside Europe where relatively high secondary impacts might be expected include North Africa, America and the Middle East.
\end{abstract}

Aris Christodoulou

aris.christodoulou@ec.europa.eu

1 European Commission, Joint Research Centre (JRC), Edificio Expo, c. Inca Garcilaso 3, 41092 Seville, Spain

2 Istanbul Technical University, Istanbul, Turkey 
Keywords Climate change $\cdot$ Sea-level rise $\cdot$ Ports $\cdot$ Maritime transport $\cdot$

Hinterland $\cdot$ Foreland

\section{Introduction}

Seaports are designed to be resilient to various stresses along their life span, but they can be vulnerable to extreme weather events that may cause disruption to operations. Climate change is expected to increase the frequency and magnitude of such events. Discrete events, such as exceptionally strong storms or longer-term changes like sealevel rise, can have a major impact on the reliability of port services and affect the whole transport and logistics chain. The transport sector, in general, is more sensitive to extreme events, such as storm surges, flash floods and wind gusts, rather than incremental changes of temperature. The frequency and severity of extreme events increase the deterioration pace of infrastructure, as well as the probability of disruptions or delays of transport services. As a result of the projected increase in the frequency and severity of extreme events according to several climate scenarios (Vousdoukas et al. 2017; ITF 2016), significant interventions may be required in planning, design, construction, operation and maintenance of port infrastructure.

The issue is particularly important considering the significance of the maritime sector for the world economy and its prevalent role in international trade. About $80 \%$ of the world freight is transported by sea, while, in the EU, almost $90 \%$ of external trade is seaborne. Furthermore, around $40 \%$ of the freight exchanged within the EU uses maritime transport (Suárez-Alemán 2016).

There is a growing body of scientific evidence on the potential risks of sea-level rise for ports. Becker et al. (2018) analyse port vulnerability and suggest specific adaptation strategies for port stakeholders. Ports are by default particularly exposed to weather events, and major European ports exposed to such events have already taken measures and built defences against inundation and storm surges. For example, important port-cities including Rotterdam, Amsterdam and London, located in an area particularly exposed to extreme weather events, have already taken protection measures against events of high severity (Nicholls 2008) such as storm surge barriers including seawalls and dikes. Main adaptation steps include storm defences, elevation to compensate for projected sea levels and even relocation. Naturally, decisions are made considering each case separately, as construction and intervention costs are high. The cost of building an international port is around four billion Euros (Schade et al. 2006, 2013), the cost of sea wall and bulkhead construction varies between three quarters of a million and two million Euros per kilometre, and the construction cost of dikes or levees to protect against $1 \mathrm{~m}$ water level rise varies between less than a million and four million Euros per kilometre (Hippe 2015).

Nevertheless, the Intergovernmental Panel on Climate Change (IPCC) scenarios (Meehl et al. 2007) project, by 2100, a global mean temperature rise between 2 and $6{ }^{\circ} \mathrm{C}$ in comparison to pre-industrial levels. To better understand and predict the effects of such changes, different climate change scenarios, both low- and high-end, should be considered. According to Hallegatte et al. (2013): "Average global flood losses in 2005 are estimated to be approximately US\$ 6 billion per year, increasing 
to US\$ 52 billion by 2050 with projected socioeconomic change alone. With climate change and subsidence, present protection will need to be upgraded to avoid unacceptable losses of US\$ 1 trillion or more per year". The impacts of climate change on transport will likely be widespread and vary from region to region. Lam and Su (2015) and Novati et al. (2015), discuss the risks of disruptions in ports due toamong others- natural events, and both works suggest that the impacts on the rest of the transport chain are considerable.

In the methodology presented here, the analysis of risk for individual ports is combined with the analysis of the network of port connections on both the land and the sea side. This approach permits the quantification of the potential risk of disruption for each port itself, as well as the evaluation of the risks for the port's hinterland and foreland. The starting point of the analysis of the impacts of climate change on seaports was the work carried out in the context of the HELIX project ${ }^{1}$ (HighEnd cLimate Impacts and eXtremes,) and was part of the work on the assessment of the impacts of climate change on transport. Furthermore, the approach presented here builds on the work that was done for the PESETA III project (Christodoulou and Demirel 2017). With the help of data on coastal inundation under different scenarios, it is possible to identify European ports at risk and, as a result, quantify the impacts in different years and for events of different severity. In order to provide a more complete view of the effects of potential disruption of port operations, the impacts on hinterland and foreland are also considered.

The paper is divided in three main parts. Initially, the analytical approach is discussed, followed by details regarding the data used, and finally, results regarding the analysis of the impacts on seaports are presented.

\section{Risks of coastal inundation for European ports and maritime transport}

Inundation due to sea-level rise and storm surges could cause both temporary and permanent flooding and such impacts are already observed. Seaports will be strongly affected by sea-level rise and storm surges. Specifically, 64\% of all seaports are expected to be inundated according to the projected (IPCC 2012) global mean sea levels and combined effects of tides, local waves, and storm surges. According to the PESETA III project, the number of ports that face the risk of inundation in 2080 is expected to increase drastically in comparison to 2030 - the number of seaports to be exposed to inundation levels higher than $1 \mathrm{~m}$ is projected to increase by $80 \%$ from 2030 to 2080 . This trend is particularly strong in the North Sea, where many important ports are located, handling cargo traffic amounting to $15 \%$ of the world total. (EUCC-D 2013).

Measuring the impacts of climate change on ports is a particularly challenging task. The combination of the uncertainty of the projections, and data with the level of detail required to evaluate the effects, complicate both the identification of

1 https://www.helixclimate.eu/. 
seaports at risk and the assessment of impacts. The complication increases with the size of the area and the number of ports covered, while the analytical approach has to be selected taking into account the available data. With these limitations in mind, our aim is to provide an indication of the impacts of coastal inundation due to climate change on ports in Europe.

Although sea-level rise and extreme weather events might affect all ports, the level and duration of the impacts cannot be independent of the existence of protection measures. Several ports, many of them major ones, are already protected against flooding and storm surges. For example, Rotterdam, Amsterdam and London are known to be protected against a 1 in 1000-year event — an event of high severity projected to occur once every one thousand years-(Nicholls 2008). In fact, the Rotterdam protection measures are of the highest level globally, consisting of different storm surge barriers two of which are the largest in the world. London's flood barrier is also among the biggest in the world, while other ports have also taken protection measures against storm surges (Sigma Plan in Belgium, storm surge protection plan of the port of Hamburg etc.). Even in these cases though, upgrading of the existing flooding defences will probably be necessary in response to the projected sea-level rise.

Furthermore, there are ports that are physically protected (i.e. harbours) and can be relatively more easily defended against rising sea levels. Among those are ports that are not located on coastal- but inland areas such as Amsterdam, Hamburg, Antwerp, Ghent, Gothenburg and London, to mention only some of the major ones.

Defences against storm surges will protect port infrastructure from damages and might allow the continuation of some port operations -by protecting the port from inundation-, but they will also restrict the movement of ships. Hence, even in ports with protection measures in place, operations will likely be affected by extreme weather events.

For the evaluation of the risks of sea-level rise and coastal inundation due to climate change, water level estimates are combined with the geospatial ports' database provided by Eurostat (Geodata in GISCO of Eurostat) to identify the ports that face the highest risk to be affected by inundation and extreme weather events according to the Extreme Sea Level (ESL) ${ }^{2}$ projections (Vousdoukas et al. 2016a, b).

To identify ports at risk, we followed a simplified approach for the association of ports with water levels. Ports at risk are indicated by the ESL increase, assuming that increases are potential danger for the ports, while the level of the danger depends on the level of the increase.

We estimate the risk of sea-level rise and associated implications for all seaports in Europe that handle more than 0.5 million tonnes of cargo annually. The size of ports is determined by the gross weight of goods handled annually and represents a 2006-2016 average.

\footnotetext{
2 "The Extreme Sea Level (ESL) dataset presents the distribution of the total water level (TWL) design conditions at the European coastline. The TWL is estimated from the dynamical simulation of the major hydrodynamic sea level components (being the mean sea level, tides, storm surges and waves) as derived from an ensemble of 6 climatic models..." (Vousdoukas et al. 2016a).
} 
To measure the impacts of sea-level rise and extreme weather events, each port is associated with the respective level of ESL, or ESL increase, which indicates the level of risk. The freight activity and port calls data, which are assumed to remain unchanged over the period considered, i.e. until the end of the century, can then be used to quantify the impacts of seizing (due to closure of the port) or interruption of port services.

In order to compare the impacts of different warming levels, the ESL estimates of different scenarios are used. The RCP4.5 and RCP8.5 scenarios represent the impacts of the different global warming levels under examination. More specifically, according to Vousdoukas et al. (2017), "RCP4.5 and RCP8.5 scenario correspond to a likely global mean temperature increase of $2.0-3.6{ }^{\circ} \mathrm{C}$ and $3.2-5.4{ }^{\circ} \mathrm{C}$, in 2081-2100, above the 1850-1900 levels".

\subsection{Impacts on hinterland}

Ports are gateways of Europe to the world and a significant part of European trade is passing through its ports. As a result, any disruption of port operations is bound to also affect non-coastal regions that connect to ports through road, rail and inland waterways networks, and rely on ports for their import or export of goods. Impacts on hinterland are quite difficult to quantify, however, and one of the difficulties has to do with the lack of availability of trade data between a port and its hinterland.

For the assessment of the impacts on hinterland, a simplified approach is followed here: At first, for each NUTS3 ${ }^{3}$ region, the five seaports closest to the centroid of the region are selected, assuming that each region is predominately relying on its five nearest major ports. Then, an impact indicator $S_{\mathrm{R}}$ is calculated for each region, according to the following formula:

$$
S_{R}=\sum_{p \in P_{R}} S_{p} T_{p} / \sum_{p \in P_{R}} T_{p}, P_{R}=\left\{p_{1}, p_{2}, p_{3}, p_{4}, p_{5}\right\}
$$

where

$S_{p}$ is the sea-level rise indicator (measured in $\mathrm{m}$ ), the one used in this case is ESL change from 2010 to 2100 , at port $p$.

$T_{p}$ is the gross weight of goods handled in port $p$ annually.

$P_{R}$ is the set of ports $p$ that are closest to the centroid of region $R$

The indicator $S_{R}$ is used as a qualitative measure of the impacts on hinterland ranging from 'Low' to 'High' with two intermediate categories: 'Low- Medium', 'Medium-High'.

\footnotetext{
3 The NUTS (nomenclature of territorial units for statistics) classification divides the EU area to regions while the third level (NUTS3) represents small regions. More information can be found in EUROSTAT: https://ec.europa.eu/eurostat/web/nuts/background.
} 


\subsection{Impacts on foreland}

As in the case of hinterland, the main objective of looking at the impacts on foreland is to provide a more comprehensive view of the coastal impacts of climate change on port operations by considering wider implications. For the moment, the impacts of coastal inundation are only available for Europe, and the impacts on foreland regard the secondary effects that sea-level rise in European ports will have at global scale.

The impact of sea-level rise on a European port's foreland is analysed by identifying the connected ports that might be affected as a result of a disruption of the port's operation. The vessels database (Christidis and Rozsai 2015) provides port connectivity indicators that estimate the share of each port's traffic per corresponding port of origin or destination. The database uses Automatic Identification System (AIS) data that was collected for the period 2012-2014 and covers the global maritime fleet (ExactEarth 2015). These indicators are used to calculate for each foreland port the share of traffic from European ports projected to be exposed to sea-level rise:

$$
F_{q, S}=\sum_{p \in S p} T_{p-q} / T_{q}
$$

where

$F_{q, S}$ is the share of foreland port $q$ traffic that has an origin/destination in a port $p$ with a sea-level indicator $S$

$T_{q}$ is the total traffic of foreland port $q$

$T_{p-q}$ is the total traffic between each port $p$ and foreland port $q$

$S_{p}$ is the sea-level rise indicator, the one used in this case is Extreme Sea Level change from 2010 to 2100 , at port $p$.

\subsection{Data}

The ports in risk of inundation are identified with the help of the ESL data produced by Vousdoukas et al. (2016a, b; Vousdoukas et al. 2017). The data refer to the distribution of Total Water Level at the European coastline, which has been estimated considering the major hydrodynamic sea-level components, i.e. mean sea level, tides, waves and storm surges. The data are derived from an ensemble of climatic models based on the RCP4.5 and RCP8.5 scenarios. More information can be found in Vousdoukas et al. (2016a, b).

The data files include two variables, ESL and Episodic Extreme Water Level (EEWL) that are available for different return periods ${ }^{4}$ (ranging from 10 to 1000 year) and years (from 2010 to 2100). Furthermore, as sea-level rise data are

\footnotetext{
4 The return period is used to express the probability of occurrence of an event and it represents the time interval between events of similar intensity. For example, an event with 100 -year return period refers to an event that is estimated to occur once every 100 years. The inverse of the return period represents the probability for an event to occur in any 1 year, i.e. an event with 100 -year return period has $1 \%$ probability to occur in any 1 year.
} 
the outputs of the ensemble of different General Circulation Models (GCMs) and considerations of different ice-sheet and glacier-melt contributions, the maximum, minimum and mean relative sea-level rise values have been estimated for each scenario. In the analysis here, mainly the mean ensemble values are used that represent the most likely scenario.

According to the ESL projections, the largest increases of Mean Sea Level will take place at the North Sea, on the Atlantic coasts, and at the Black Sea, while the smallest in the Baltic Sea as a result of the land uplift in the area (Vousdoukas et al. 2017). At the same time, the uncertainty of the relative sea-level rise projections (combining sea-level rise with land uplift/subsidence projections) is higher at the North Sea than at the Mediterranean Sea and Atlantic coasts, while the uncertainty of the projections of waves and storm surges is in general higher in comparison to the relative sea-level rise projections (Vousdoukas et al. 2017).

The increase of ESLs is to a large extent driven by relative sea-level rise, with the exception of certain regions such as the Baltic Sea where waves and storm surges outweigh the impacts of land uplift. The opposite effect is projected along the Portuguese coast and the Golf of Cadiz, where the reduction of the impacts by waves and storm surges offsets relative sea-level rise (Vousdoukas et al. 2017).

Data on the location of ports were obtained from the geospatial database of seaport infrastructure provided by Eurostat (Geodata in GISCO of Eurostat) that consists of a point feature class and contains 2440 ports including all types of infrastructure from small ports and marinas to major ports. Point coordinates are derived from several input sources, including port lists from EMSA, Lloyds, Norie's Seaports of the World, the GISCO Ports dataset and the UN/LOCODE 2007 list. The geospatial database includes the main characteristics of the ports that help with their identification.

The geospatial database of ports has been combined with Eurostat data on the gross weight of goods handled in ports. As a result, 1428 ports were selected. The data used refer to total cargo handled and the values are averages for the period 2006-2016.

Data on foreland ports were extracted from the JRC-Vessels database. This database is based on Automatic Identification System (AIS) micro data that allows the ship movements of the world maritime fleet to be tracked. The port calls of each ship itinerary are transformed into a set of bilateral port connections, depending on the frequency of itineraries that call at both ports. The network of bilateral port connections, for containerships and dry bulk ships, is normalised using port traffic statistics and allows the estimation of traffic volumes between any pair of ports globally. The specific data used here refer to the year 2014.

\section{Results}

\subsection{Present-day extreme sea levels}

For the impacts to be assessed, it is important to have information not only on the severity of the event but also on frequency and duration. Regarding frequency, 


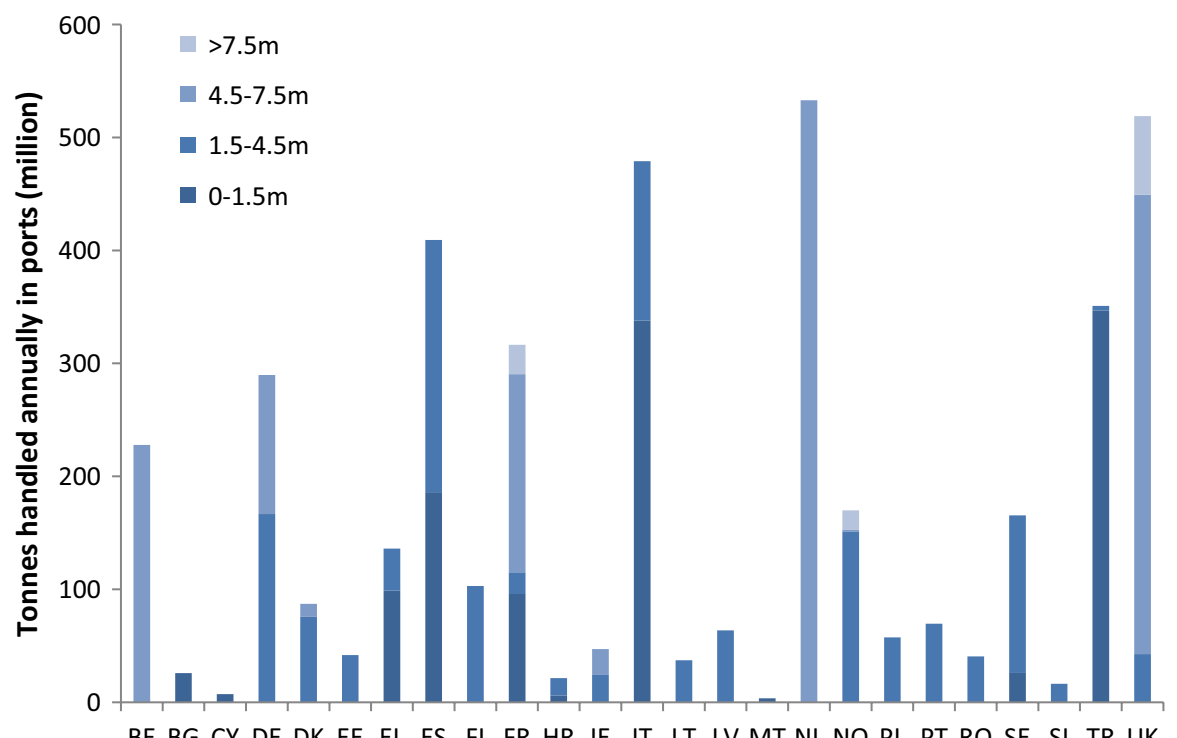

Fig. 1 Gross weights of cargo handled in ports affected by present-day ESL ${ }_{100}$ in European countries

Table 1 Ports affected in Europe by present-day $\mathrm{ESL}_{100}$ and gross weight of goods handled annually

\begin{tabular}{lcc}
\hline ESL $(\mathrm{m})$ & Ports & Tonnes (millions) \\
\hline $0-1.5$ & 128 & 1135 \\
$1.5-3$ & 159 & 1021 \\
$3-4.5$ & 66 & 448 \\
$4.5-6$ & 41 & 719 \\
$6-7.5$ & 39 & 783 \\
$>7.5$ & 16 & 113 \\
\hline
\end{tabular}

Vousdoukas et al. (2017) have estimated that present-day 100-year ESL "is projected to occur approximately every 11 years by 2050, and every 3 and 1 year by 2100 under RCP4.5 and RCP8.5, respectively". Moreover, "some regions are projected to experience an even higher increase in the frequency of occurrence of extreme events, most notably along the Mediterranean and the Black Sea, where the present day 100 year ESL is projected to occur several times a year" (Vousdoukas et al. 2017). However, without incorporating information relevant to the vulnerability and resilience of ports, it is very difficult to infer the level of impacts.

In this study, Extreme Sea Level data are used to classify areas according to the potential impact. The highest values are projected to occur in the North Sea and the Atlantic coast.

In Table 1, the total number of ports and cargo handled (referring to annual average values of the period 2006-2016) to be affected in Europe during a 100-year event, by different water levels, are presented, while in Fig. 1, per country results 


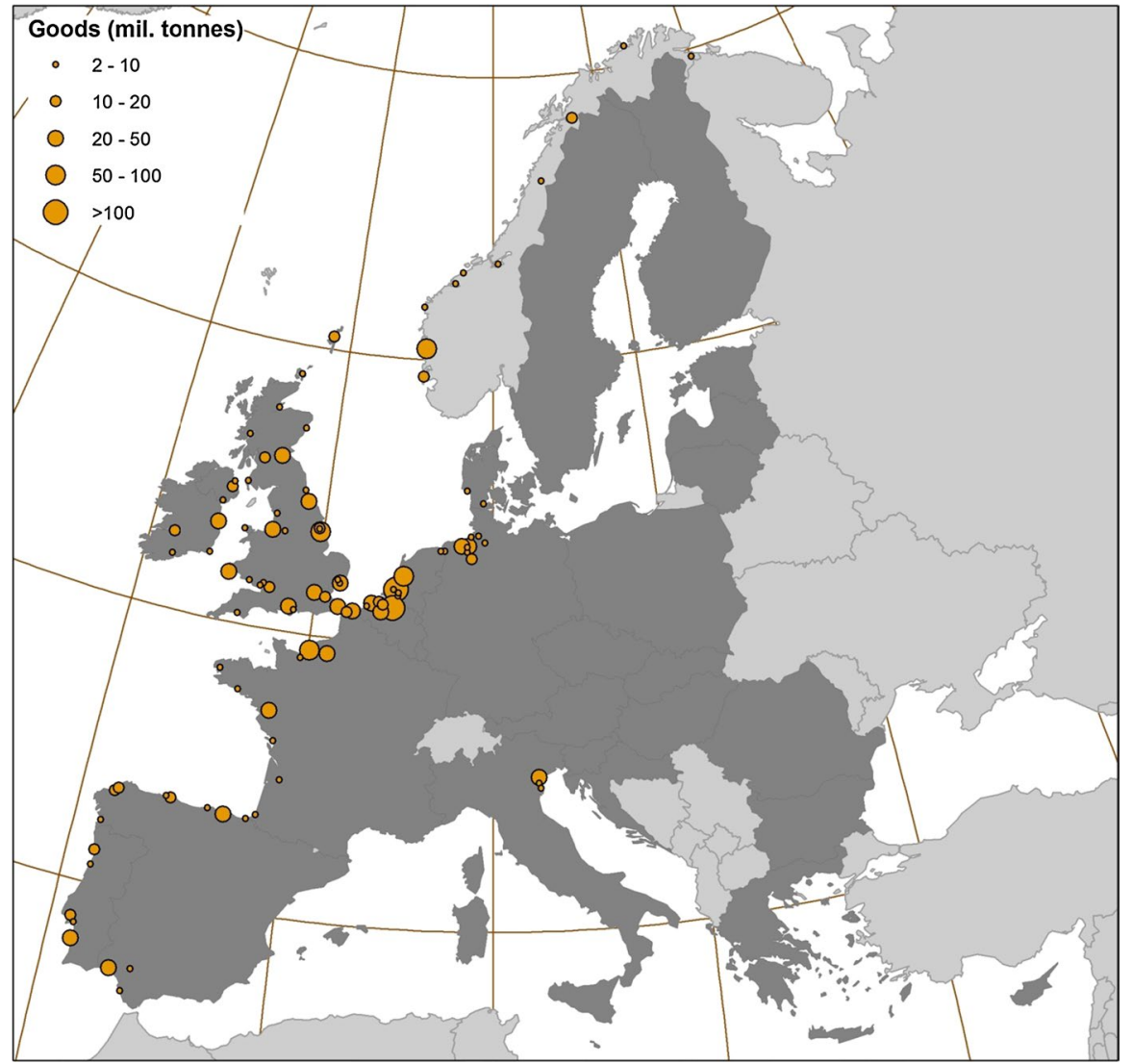

Fig. 2 Large ports (handling more than 2 million tonnes annually) exposed to higher than 3 m presentday $\mathrm{ESL}_{100}$

are shown. Disruptions to be caused by ESL higher than $3 \mathrm{~m}$ are projected to affect ports that handle in total more than 2 billion tonnes of cargo annually after 2050, according to RCP8.5.

In the Black Sea and the Mediterranean, the impacts are projected to be milder but much more frequent. For example, in many parts of the Mediterranean, ESL 100 (i.e. 100-year ESL) is projected to take values in the range of 1 and $2 \mathrm{~m}$, and to occur 5 times per year between 2050 and 2100 according to RCP8.5. In the Black Sea, where ESL values are lower, ESL is projected to occur 10 times per year. On the other hand, in the North Sea, where $\mathrm{ESL}_{100}$ values are much higher, often more than $6 \mathrm{~m}, \mathrm{ESL}_{100}$ is projected to occur once every 2 years after 2050 (Vousdoukas et al. 2017).

The countries to be affected mostly include those with ports on the North Sea, i.e. UK, Germany, Belgium, France and the Netherlands.

Finally, in Fig. 2, all ports handling more than 2 million tonnes annually, to be exposed to higher than $3 \mathrm{~m}$ water levels, are shown. As seen in the figure, the 
Table 2 Additional ports to be affected in Europe by an increase of ESL from 2010 to 2100 (100-year event) and gross weights of goods handled annually (referring to annual average of gross weights of goods handled in ports during the period 2006-2016)

\begin{tabular}{llllll}
\hline ESL $(\mathrm{m})$ & $\mathrm{RCP} 4.5$ & & $\mathrm{RCP} 8.5$ & \\
& Ports & Tonnes (millions) & & Ports & $\begin{array}{l}\text { Tonnes } \\
\text { (mil- } \\
\text { lions) }\end{array}$ \\
\hline $1.5-4.5$ & 79 & 843 & 65 & 740 \\
$>4.5$ & 29 & 164 & 40 & 208 \\
\hline
\end{tabular}

majority is in ports on the North Sea, while a few appear also on the Atlantic Coast and the Adriatic Sea.

\subsection{Extreme sea-level increase}

The impacts of sea-level rise are also assessed for the two scenarios with the help of the projections of increase of ESL from 2010 to 2100 for 100-year return period. According to RCP8.5, for most part of the coastline, there will be ESL increases higher than $0.5 \mathrm{~m}$, while increases larger than $1 \mathrm{~m}$ are projected to occur in the North Sea, the Western part of the Baltic Sea and in parts of the British and French Atlantic coasts.

In Table 2, we present estimates of the additional number of ports and cargo (referring to annual average of gross weight of goods handled in ports during the period 2006-2016) in Europe, to be exposed to certain ESLs from 2010 to 2100.

According to RCP8.5, in 2100 more than 200 million additional tonnes will be handled annually in ports, to be affected by ESL higher than $4.5 \mathrm{~m}$, compared to 2010. Comparing the two scenarios, according to RCP8.5, additional ports, handling annually 44 million tonnes, will be affected by ESL higher than $4.5 \mathrm{~ms}$ in 2100 , in comparison to 2010, than what is projected by RCP4.5. The additional ports projected to be exposed to ESL higher than $4.5 \mathrm{~m}$ in 2100 than in 2010 are located in Spain, UK, Ireland, Portugal and Norway. Obviously, this has to do with the thresholds set, as countries such as Belgium and the Netherlands are already exposed to ESL higher than $4.5 \mathrm{~m}$. Furthermore, from the analysis at country level, it is shown that in many countries there is an increase in the ports exposed to water levels higher than $1.5 \mathrm{~m}$. For example, according to the RCP8.5 projections, in France in 2010, around $30 \%$ of the total cargo handled annually is handled in ports exposed to less than $1.5 \mathrm{~m}$ ESL, while in 2100 there are no ports exposed to ESL below $1.5 \mathrm{~m}$ and $30 \%$ of the total cargo is handled in ports exposed to ESL between 1.5 and $4.5 \mathrm{~m}$; the rest of the cargo is handled in ports exposed to ESL of more than $4.5 \mathrm{~m}$.

\subsection{Impacts on hinterland}

In Fig. 3, the results regarding the impacts on hinterland are presented. The colour variation reflects impact variations according to the increase of ESL from 2010 to 

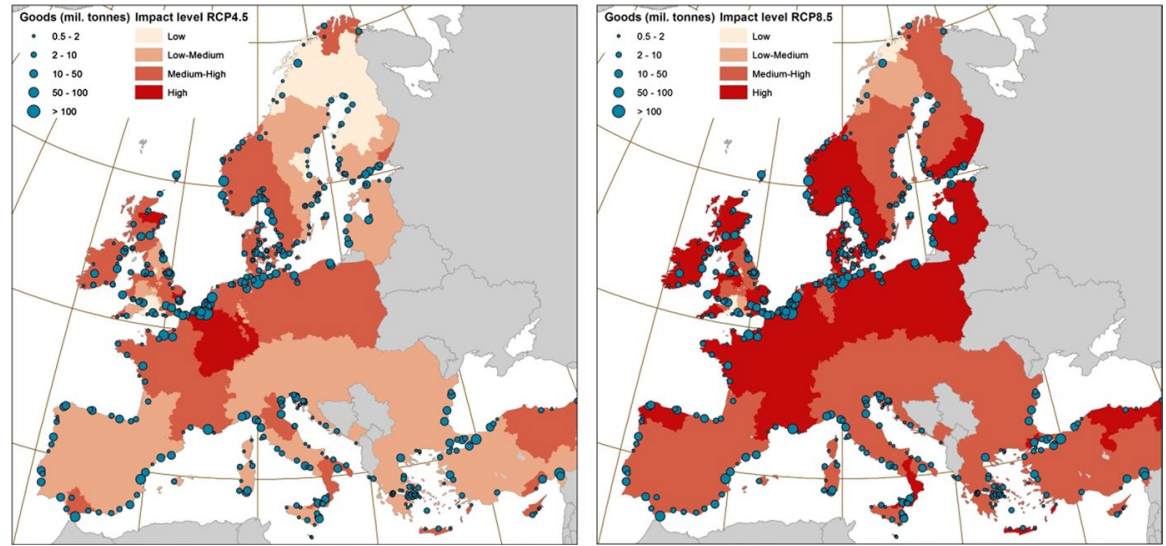

Fig. 3 Impacts of the ports affected by $\mathrm{ESL}_{100}$ increase from 2010 to 2100 on hinterland (NUTS3 regions) according to RCP4.5 (left) and RCP8.5 (right)

2100. More specifically the following thresholds have been used to classify the level of potential impacts:

- Low ESL $2100-E S L_{100}^{2010}<0.25 \mathrm{~m}$.

- Low-medium $0.25 \mathrm{~m} \leq E S L_{100}^{2100}-E S L_{100}^{2010}<0.5 \mathrm{~m}$.

- Medium-high $0.5 \mathrm{~m} \leq E S L_{100}^{2100}-E S L_{100}^{2010}<0.75 \mathrm{~m}$.

- High ESL $L_{100}^{2100}-E_{100}^{2010} \geq 0.75 \mathrm{~m}$.

The regions that appear red are those projected to be most severely affected, as they are predominately served by ports projected to be exposed to high ESL increases. The regions to be mostly affected are in Germany, the Netherlands, Belgium, France, Denmark, Sweden, Norway, Poland and the Baltic countries. There are also regions to be severely affected in the UK, Spain, Italy and Turkey.

The impacts represented here are only secondary impacts of the disruption of port operations. Coastal inundation and flooding can also affect the connections to the hinterland by interrupting the operations of road-, rail- and inland waterway networks. However, these effects are not considered here, and the focus remains on the operation of ports.

The impact measure is qualitative and is associated with the increase of ESL. The measure aims to indicate the risk that hinterland areas face according to the exposure of ports to ESL. The assumption that proximity is the main factor that determines the reliance of a region to a port plays clearly an important role in shaping the result.

\subsection{Impacts on foreland}

Finally, in Figs. 4 and 5 the impacts on ports worldwide are illustrated. These results have been produced with the help of data on port calls and they refer to the secondary effects of the disruption of European port operations as a result of the projected 


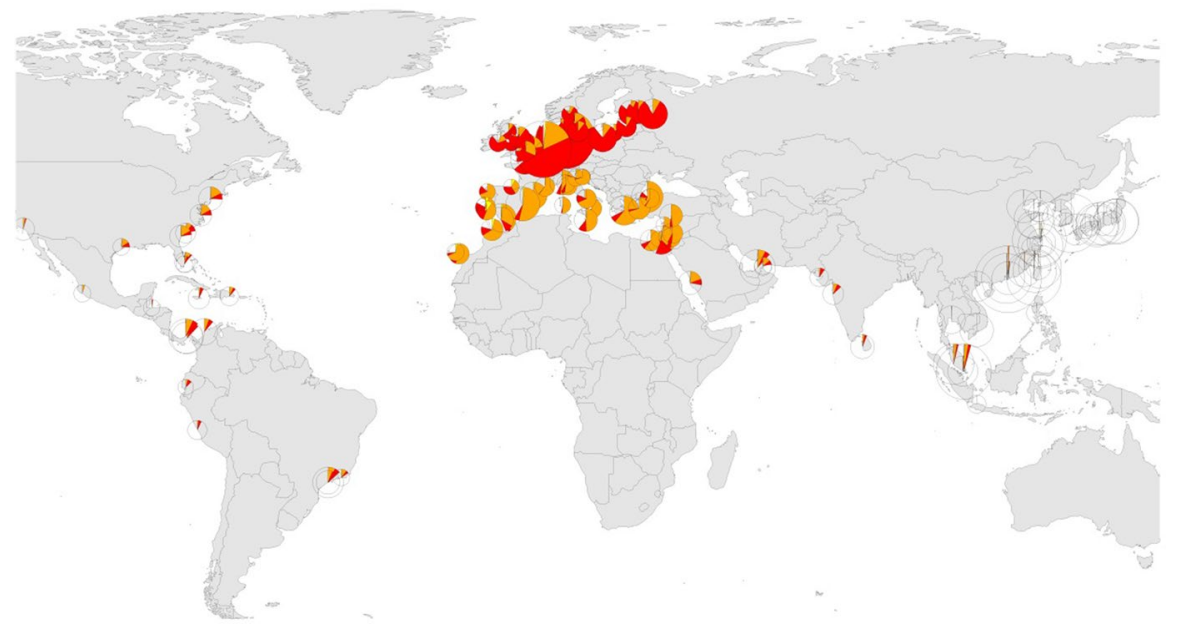

Fig. 4 Worldwide links of European ports affected by ESL increase according to RCP8.5

Fig. 5 Links of European ports affected by ESL increase according to RCP8.5

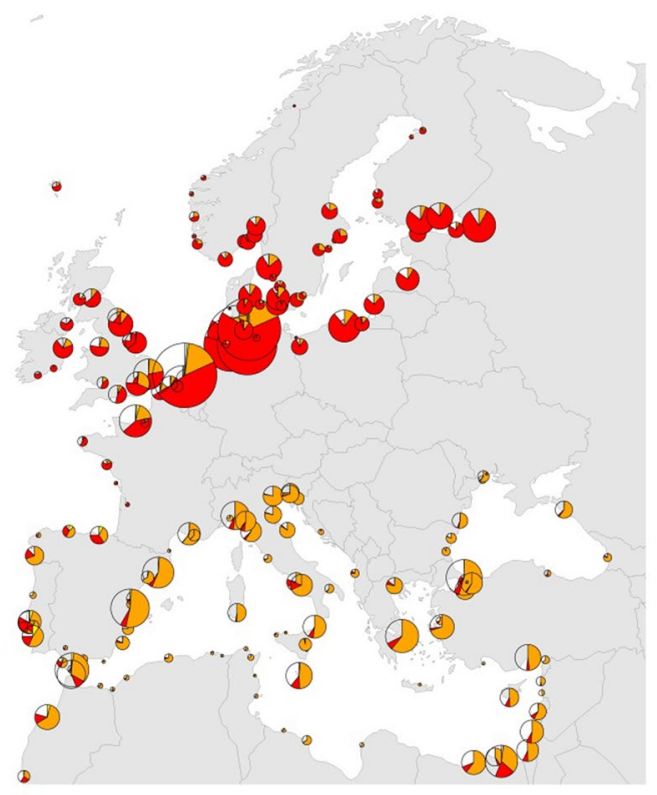

increase of ESL until 2100. The data are used to extract information on connections of container ports worldwide. The size of the pies represent the total number of connections or port calls and the coloured pieces of the pies represent the part of the total connections to ports exposed to different levels of ESL increases. The same ESL thresholds as in the previous section (impacts on hinterland) have been used 
and the colour variations correspond to potential impacts according to the following classification:

- Transparent Low

- Yellow Low-medium

- Orange Medium-high

- Red High

The highest secondary impacts appear to occur in Europe and specifically North Europe which is also the area where the highest ESL increases are projected to take place. Most likely, this is the result of the fact that containerships call at various European ports when in the area. Areas out of Europe where relatively high secondary impacts might be expected include North Africa, America and the Middle East. Ports in the Far East seem to be only marginally affected. This reflects the fact that only a relatively low share of their traffic, which depends on connections with European ports, is affected by sea-level rise.

\section{Conclusions}

For the analysis of the impacts of climate change on seaports, European ports are covered focusing on those handling more than 0.5 million tonnes annually, while their risk level is associated to present-day ESL and the increase of ESL from the present to 2100. Following the evaluation of port risks according to their projected exposure to sea-level rise and extreme weather events, the level of impacts can be measured in relation to the volumes of cargo handled annually. Furthermore, the results are aggregated at country level, and it is possible to see which countries are already threatened by particularly high water levels and which countries' exposures are expected to change in the future.

Our study benefits from available data sources; the ESL data offer a good opportunity for analysis at the geographical level and for the RCP scenarios they are available. At first, data on present-day ESL, in combination with information on corresponding frequencies, provide an indication of the projected disruptions and their spatial distribution. The differences between the scenarios regarding global temperature increase are assessed by comparing the RCP4.5 and RCP8.5 scenarios, and they refer to the number of additional ports to be exposed to high ESL from 2010 to 2100. According to the RCP8.5 scenario, it is estimated that the cargo volume to be handled in the additional ports, to be exposed to ESL higher than $4.5 \mathrm{~m}$ from 2010 to 2100 , is $25 \%$ higher, compared to the RCP4.5 scenario.

Following the identification of major ports at relatively high risk, the wider impacts of potential disruption of port operations are evaluated by considering the effects on hinterland in Europe and on foreland worldwide. Such an assessment is particularly challenging in view of the level of information available. From the analysis of the impacts on hinterland, it has been possible to assess the risk for European regions based on the risk level of ports in proximity. From the analysis of the impacts on foreland, it has been possible to identify European and overseas 
destinations to be mostly affected, based on their connections with European ports at risk.

The mapping of the hinterland affected by sea-level rise suggests that a much wider area than the immediate zone surrounding each port should be concerned. Ports have a wide catchment area that covers most of central Europe. Disruptions in the operation of a port would directly affect road, rail and inland waterways services connected to it and-as a result-hinder transport and trade for the goods and the origins-destinations served by the port in question.

On the foreland side, the results highlight the impact of the high degree of interdependence of ports on global level. A disruption in the operations of even a limited number of European ports, due to sea-level rise, can have repercussions on the operations of ports in different geographical areas that are part of common supply chains. The impact is quite pronounced within Europe, where more than $60 \%$ of port traffic is dependent on connections with ports having a high sea-level rise risk. It is worth noting that, while Mediterranean ports are not expected to suffer much from sea-level rise, the indirect impacts on their operations, because of possible disruptions in Northern European ports, can be considerable. A similar impact -though at a much lower scale- can be expected for the East U.S. coast, Brazil and traffic through the Panama Canal.

Acknowledgements We would like to thank the reviewers for their thorough reviews and all their comments which definitely helped us to a great extent in improving the paper.

Disclaimer The views expressed are purely those of the authors and may not in any circumstances be regarded as stating an official position of the European Commission.

Open Access This article is distributed under the terms of the Creative Commons Attribution 4.0 International License (http://creativecommons.org/licenses/by/4.0/), which permits unrestricted use, distribution, and reproduction in any medium, provided you give appropriate credit to the original author(s) and the source, provide a link to the Creative Commons license, and indicate if changes were made.

\section{References}

Becker, A., A. Ng, D. McEvoy, and J. Mullet. 2018. Implications of climate change for shipping: Ports and supply chains. WIREs Climate Change 9 (2): 508. https://doi.org/10.1002/wcc.508.

Christidis, P. and M. Rozsai. 2015 Port connectivity indicators using AIS data. Maritime Connectivity in the Mediterranean. Center for Mediterranean Integration, Marseille, France. JRC 95978.

Christodoulou, A. and Demirel, H. (2017) Impacts of Climate Change on Transport - A focus on airports, seaports and inland waterways, EUR 28896 EN, Publications Office of the European Union, Luxembourg, ISBN 978-92-79-76902-3, https://doi.org/10.2760/447178, JRC108865.

EUCC-D. 2013. Coastal \& marine, Coastal climate change, ports and renewable energies: Impacts, vulnerabilities and adaptation 22(1).

ExactEarth. 2015. Purchase of access to automatic identification system (AIS) ship positions database. Contract No. 154662-2014-A07-CA, Final Deliverable, European Commission.

Hallegatte, S., C. Green, R.J. Nicholls, and J. Corfee-Morlot. 2013. Future flood losses in major coastal cities. Nature Climate Change 3: 802-806.

Hippe, A., A. Becker, M. Fischer B. and Schwegler. 2015. Estimation of cost required to elevate US ports in response to climate change: A thought exercise for climate critical resources. Stanford University, Center for Integrated Facility Engineering: CIFE Working Paper WP138. 
IPCC (Intergovernmental Panel on Climate Change). 2012. Special report on managing the risks of extreme events and disasters to advance climate change adaptation (SREX). Cambridge, U.K.: Cambridge University Press.

ITF. 2016. Adapting transport to climate change and extreme weather: implications for infrastructure owners and network managers. ITF Research Reports, OECD Publishing, Paris, https://doi. org/10.1787/9789282108079-en.

Lam, J.S.L., and S. Su. 2015. Disruption risks and mitigation strategies: an analysis of Asian ports. Maritime Policy \& Management 42 (5): 415-435. https://doi.org/10.1080/03088839.2015.1016560.

Meehl, G.A., T.F. Stocker, W.D. Collins, P. Friedlingstein, A.T. Gaye, J.M. Gregory, A. Kitoh, R. Knutti, J.M. Murphy, A. Noda, S.C.B. Raper, I.G. Watterson, A.J. Weaver and Z.C. Zhao. 2007. Global climate projections. In Solomon, S. ed. Climate Change 2007: The Physical Science Basis. Contribution of Working Group 1 to the Fourth Assessment Report of the Intergovernmental Panel on Climate Change, Cambridge University Press, Cambridge, United Kingdom and New York, NY, USA.

Nicholls, R. et al. 2008. Ranking Port Cities with High Exposure and Vulnerability to Climate Extremes: Exposure Estimates, OECD Environment Working Papers, No. 1, OECD Publishing, Paris.

Novati, M., P. Achurra-Gonzalez, R. Foulser-Piggott, G. Bowman, M.G.H. Bell and P. Angeloudis. 2015. Modelling the effects of port disruption: assessment of disaster impacts using a cost based container flow assignment in liner shipping networks. Transportation Research Board 94th Annual Meeting, Washington D.C. USA.

Schade, W., C. Doll, M. Maibach, M. Peter, F. Crespo, D. Carvalho, G. Caiado, M. Conti, A. Lilico and N. Afraz. 2006. Analysis of the contribution of transport policies to the competitiveness of the EU economy and comparison with the United States. COMPETE Final Report, funded by European Commission-DG TREN. Karlsruhe, Germany.

Schade, W., F. Senger, W. Rothengatter, O. Meyer-Rühle and I.S. Brouwer. 2013. TEN-T Large projectsInvestments and costs. Study prepared for Directorate-General for Internal Policies, Policy Department B: Structural and Cohesion Policies, Transport and Tourism. European Parliament, Brussels.

Suárez-Alemán, A. 2016. Short sea shipping in today's Europe: A critical review of maritime transport policy. Maritime Economics \& Logistics 18 (3): 331-351.

Vousdoukas, M., L. Mentaschi, E. Voukouvalas, M. Verlaan and L. Feyen. 2016a. Extreme Sea levelRCP85. European Commission, Joint Research Centre (JRC) [Dataset] PID: http://data.europ a.eu/89h/a565eea4-5422-4c7d-a000-2e10ae872da7.

Vousdoukas, M., L. Mentaschi, E. Voukouvalas, M. Verlaan and L. Feyen. 2016b. Extreme Sea levelRCP45. European Commission, Joint Research Centre (JRC) [Dataset] PID: http://data.europ a.eu/89h/e9e42344-119d-479e-9bc7-57400d12a8a2.

Vousdoukas, M., L. Mentaschi, E. Voukouvalas, M. Verlaan, and L. Feyen. 2017. Extreme sea levels on the rise along Europe's coasts. Earth's Future 5: 304-323. https://doi.org/10.1002/2016EF000505. 